\title{
РАСЧЛЕНЕНИЕ ОРДОВИКСКОЙ КАРБОНАТНОЙ ТОЛЩИ НА РАКВЕРЕСКОМ МЕСТОРОЖДЕНИИ ФОСФОРИТОВ ПО ДАННЫМ СКВАЖИННОЙ ГЕОФИЗИКИ
}

В данной статье рассмотрены возможности использования геофизических исследований скважин (ГИС) в целях детального расчленения и корреляции разреза карбонатной толщи нижнего и среднего ордовика мощностью около 100 м, перекрывающей промышленный пласт фосфоритов и вмещающей промпласт кукерситов на Раквереском месторождении фосфоритов.

До настоящего времени в практике геологоразведочных работ используется метод макроскопического описания керна с увязкой глубин по диаграммам гамма-каротажа (ГК). При этом учитываются наиболее четкие геолого-геофизические репера, в основном описанные В. Ш. Баранкиным в 1977 г. в неопубликованном отчете о статистической обработке данных каротажа буровых скважин и составлении типичных геолого-геофизических разрезов Эстонского фосфоритного бассейна (в разрезе сверху вниз):

1. нижний контакт раквереского горизонта. (На Раквереском месторождении это контакт $\mathrm{O}_{2} r g$ и $\mathrm{O}_{2} h r-A$.Ш.) (рис. 1);

2. слой метабентонита, залегающий в основании кейлаского горизонта;

3. слой метабентонита, залегающий в верхах идавереского горизонта;

4. вокаская пачка $\left(\mathrm{O}_{1} \mathrm{kn} V\right)$ кундаского горизонта.

Кроме указанных реперов, геологи выделяют по ГК-диаграммам другие достаточно четкие контакты пластов (таблица). Однако до сих пор большие трудности вызывает расчленение по кривым ГИС толщи пород $\mathrm{O}_{2} \mathrm{id}-\mathrm{O}_{2} \mathrm{ls}$. Контакты пластов, слагающих эти горизонты, практически не отражаются на ГК-диаграммах.

Для детального расчленения и корреляции разреза на участке Кабала-Западный был использован профиль из шести скважин, пробуренных через зону аномалии низкого сопротивления, выявленную Р. Вахером наземными электроразведочными работами методом дипольного профилирования (ДП) (рис. 1). Амплитуда этой аномалии $(A)$ вычислена по формуле:

$$
A=\frac{\mathrm{Q}_{\mathrm{K} \max }}{\mathrm{Q}_{\mathrm{min}}},
$$

где @к max и @к min - соответственно максимальные и минимальные значения кажущихся сопротивлений в области аномалии (Блох, 1962). В данном случае $A \approx 2,3$. Это значение приблизительно соответствует относительной разнице в сопротивлениях ненарушенных и нарушенных пород. Ширина аномалии 140 м. Длина аномалии неизвестна (не оконтурена на западе).

Скважины пробурены с полным отбором керна. Керн изучен и описан Т. Кийпли, И. Туулингом и автором с детальностью, необходимой 


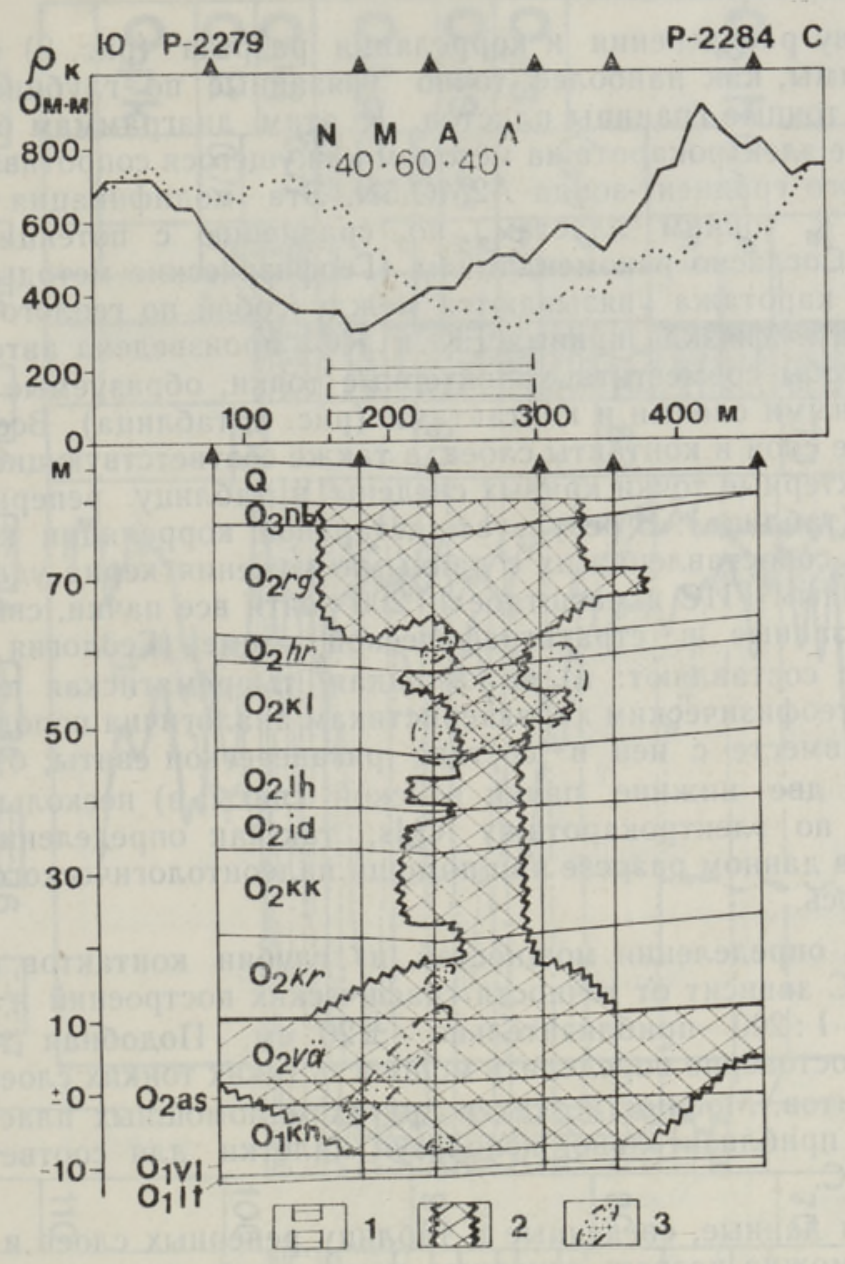

Рис. 1. Геологический разрез зоны аномалии, наверху график дипольного профилирования (ДП) по Р. Вахеру. 1 - аномалия ДП низкого сопротивления; 2 - зона доломитизации; 3 - зоны ожелезнения.

для попластовой интерпретации каротажных диаграмм в соответствии с принятой стратиграфической схемой (Геология ..., 1987), а также с целью изучения нарушения и сопутствующих ему вторичных изменений горных пород и влияния последних на результаты ГИС.

По данным изучения керна (рис. 1,2$)$, в скважине P-2281, пробуренной в осевой зоне аномалии, отмечается сильная доломитизация, кавернозность, пористость пород почти во всех свитах. Породы местами ожелезнены (красноцветны). На глубинах 29,5 и $36-36,6$ м уровня $\mathrm{O}_{2} \mathrm{kl}$ субвертикальные трещины. Первая трещина с вертикальной штриховкой скольжения и следами кальцитовой минерализации. По одной стороне керна - зона вторичного окисления с микрополосчатой текстурой. Вторая трещина мощностью 3 см заполнена кальцитом. Породы в скважинах P-2280, P-2282, Р-2283 также местами доломитизированы и ожелезнены. Из них наиболее ожелезненные породы $\mathrm{O}_{2} \mathrm{kl}$ в скважине P-2282, где тоже отмечена вертикальная трещина. В слое кукерсита $\left(\mathrm{O}_{2} \mathrm{kk} K\right)$ скважины Р-2283 вкрапленность полуокисленного пирита окаймляет включения кавернозного известняка. В целом строение данной локальной зоны нарушения и проявление доломитизации пород в ней укладываются в общую закономерность, ранее описанную М. С. Пичугиным и др. (1976). 
За основу расчленения и корреляции разреза (рис. 2) были взяты ГК-диаграммы, как наиболее точно увязанные по глубине и дающие достаточно точные границы пластов. К этим диаграммам были привязаны кривые электрокаротажа методом кажущегося сопротивления (KC) подошвенного градиент-зонда A2MO.5N. Эта модификация более чувствительна к тонким пластам, по сравнению с потенциал-зондами N 2MO.5A. Согласно рекомендациям (Геофизические методы . . , 1983), диаграммы каротажа увязываются между собой по геолого-геофизическим реперам. Увязка кривых ГК и КС произведена автором таким образом, чтобы совместить характерные точки, образуемые на кривых ГИС реперными слоями и контактами (рис. 1, таблица). Все аномалиеобразующие слои и контакты слоев, а также соответствующие им аномалии и характерные точки кривых сведены в таблицу реперных слоев и контактов (таблица). В результате детальной корреляции каротажных диаграмм и сопоставления их с данными изучения керна удалось выделить по данным ГИС в масштабе $1: 200$ почти все пачки, свиты и горизонты, указанные в стратиграфической схеме (Геология..., 1987). Исключение составляют: а) маломощная тырремягиская пачка $\mathrm{O}_{2}$ on, которая по геофизическим характеристикам аналогична породам $\mathrm{O}_{2} \mathrm{rk} T$ и выделяется вместе с ней в составе рягавереской свиты; б) суммарно выделенные две нижние пачки вяоской свиты; в) несколько условно выделенная по электрокаротажу $\mathrm{O}_{2} \mathrm{ls}$, так как определение границы $\mathrm{O}_{2} \mathrm{ls}-\mathrm{O}_{2}$ uh в данном разрезе при помощи палеонтологического метода не производилось.

Точность определения мощностей и глубин контактов пластов по данным ГИС зависит от точности графических построений и составляет в масштабе 1:200 приблизительно \pm 20 см. Подобная точность не позволяет достоверно определить мощность таких тонких слоев, как слои метабентонитов. Мощности этих и других маломощных пластов можно определить приблизительно, используя палетки для соответствующих методов ГИС.

Обобщая данные, сведенные в таблицу реперных слоев и контактов (таблица), можно назвать основные аномалиеобразующие слои изучаемой карбонатной толщи. Это слои метабентонитов, мергелей, а также слои, содержащие крупные железистые оолиты, скопления фосфатных остатков фауны или обогащенные глауконитом. На диаграммах электрокаротажа методом КС подошвенным градиент-зондом выражены также контакты чистых известняков с более глинистыми породами, контакты известняков с кукерситами. Дополнительно коррелирующиеся аномалии на диаграммах электрокаротажа связаны с закономерными колебаниями глинистости в разрезах пачек и свит. Слои более чистых пород отражаются на кривых подошвенного градиент-зонда как пласты высокого сопротивления (сверху вниз - участок кривой между минимумом и максимумом), а слои относительно более глинистых пород как пласты низкого сопротивления (участок кривой между максимумом и минимумом) (рис. 2).

Таким образом, вопрос расчленения пород $\mathrm{O}_{2} \mathrm{id}-\mathrm{O}_{2} \mathrm{ls}$, а также детального расчленения всей карбонатной толщи на Раквереском месторождении фосфоритов можно решить при помощи диаграмм электрокаротажа подошвенным градиент-зондом. Расчленение и корреляцию разреза, хотя и с некоторыми трудностями, можно проводить и в скважинах, пробуренных в осевых частях нарушений. Это дает возможность проследить по кривым ГИС не только границы пластов, но и выявить нзменения крнвых, вызванные нарушенностью пород. Этот вопрос, а также вопросы анализа мощностей и структурного анализа по полученным данным заслуживают особого рассмотрения. 
РЕПЕРНЫЕ СЛОИ И КОНТАКТЬ

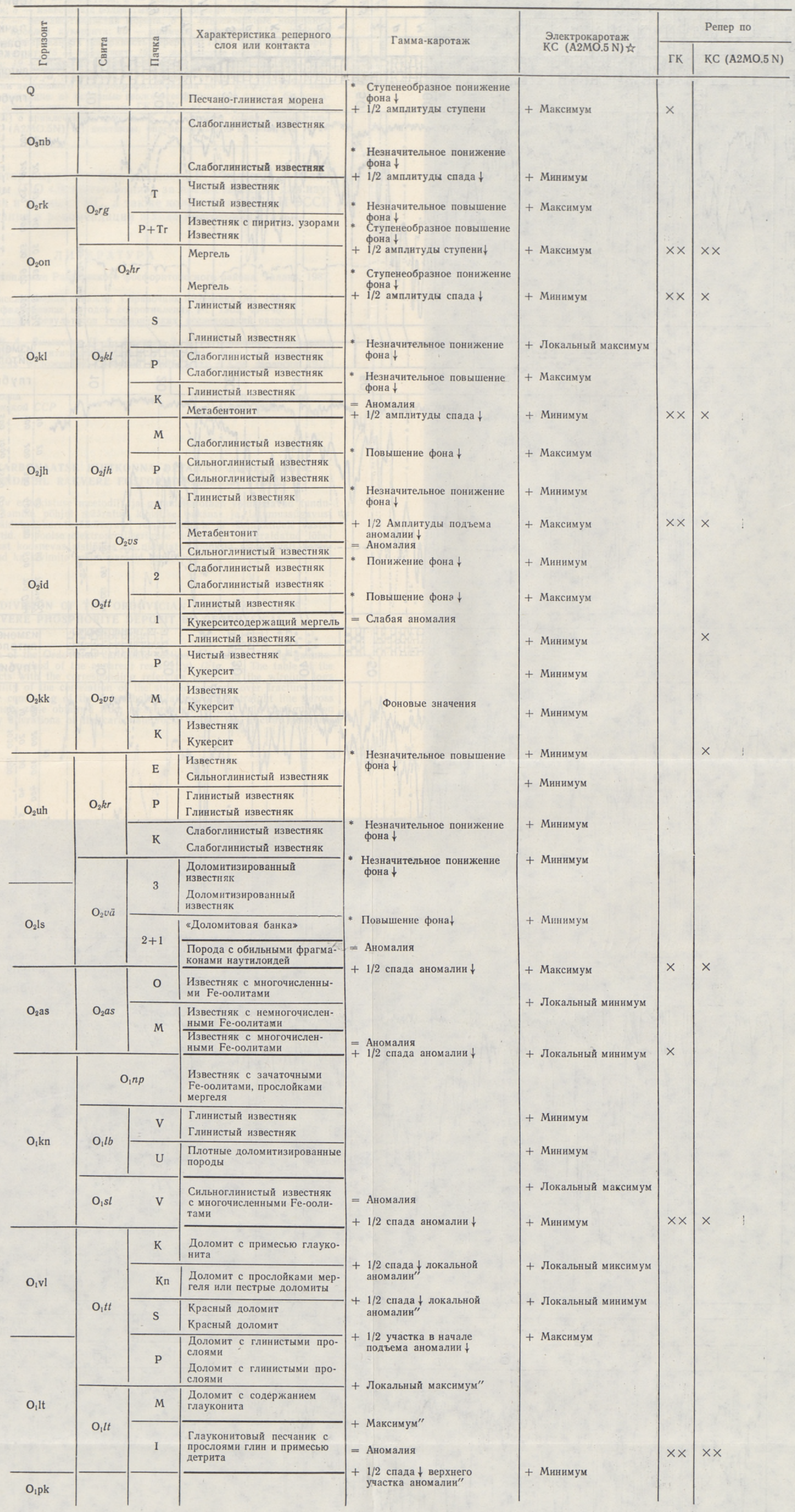

Условные обозначения

— контакт двух слоев

* Изменение фона кривой в зоне контакта слоев; + Точка кривой, соответствующая контакту слоев; = Форма кривой, соответствующая слою;

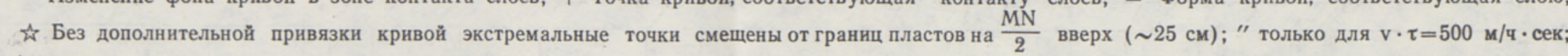
$\downarrow$ сверху вниз;

XX Геолого-геофнзнческне репера; $\times$ Достаточно четкие контакты на кривых 
Рис. 2. Схема корреляции ордовикской карбонатной толщи по геофизическим диаграммам ГK - гамма-каротажа; $\mathrm{KC}_{1}$ - электрокаротажа методом кажущегося сопротнвления подошвенным градиент-зондом $\mathrm{A} 2 \mathrm{MO} .5 \mathrm{~N} ; \mathrm{KC}_{2}$ - электрокаротажа методом кажущегося сопротивления потенциал-зондом N2MO.5A; Кав - кавернометрии. (На врезке схема расположения скважин). 1 - известняк; 2 - доломит; 3 - вторичный доломит; 4 - глинистый известняк; 5 - известняк с волнистыми прослойками мергеля; 6 - полукомковатый известняк; 7 - песчано-глинистая морена; 8 - относительные колебания глинистости пород; 9 - прослой кукерсита; $10-$ примесь кукерсита; $11-$ прослой метабентонита; 12 - пиритизированная поверхность перерыва; 13 - пиритовые узоры; 14 - пиритизированный детрит; 15 - глауконит; 16 - железистые оолиты; 17 - ожелезнение; 18 - каверны; 19 - поры; 20 - разрушенность; 21 - трещины, 22 - трещины, заполненные кальцитом; 23 - мергель; 24 - вкрапленность пирита; 25 - скважины; 26 - ось аномалии дипольного электропрофнлирования по Р. Вахеру; 27 - корреляционные линии, соединяющие: а) основные геолого-геофизические репера, б) достаточно четкие контакты, определенные по кривым ГК и КС, в) контакты, определенные по кривым КС (А2MO.5N) с привлечением кривых ГК, г) контакты, определенные только по кривым КС (А2MO.5N), д) контакты, определенные по кривым ГК.

В заключении автор выражает благодарность Р. Раудсепу, А. Паюпуу и их сотрудникам (ПО «Эстонгеология») за предоставление для изучения керна скважин и данных ГИС, а также коллегам из ИГ АН ЭССР за сделанные замечания и рекомендации в ходе подготовки статьи.

\section{ЛИТЕ РАТ УР А}

Геология и полезные ископаемые Раквереского фосфоритоносного района. Таллин, 1987, $25-66$.

Геофизические методы исследования скважин. Справочник геофизика. М., 1983.

Блох Н. М. Электропрофилирование методом сопротивления. М., 1962, 45-48.

Дахнов В. Н. Интерпретация результатов геофнзических исследований разрезов сква-

жин. М., 1982.
Пичугин М. С., Пуура В. А., Вингисаар П. А., Эрисалу Э. К. Региональные проявления метасоматической доломитизации в связи с тектоническими нарушениями в нижнепалеозойских отложениях Северной Прибалтики // Сов. геология, 1976, № $10,78-90$.
Институт геологии
Академии наук Эстонской ССР
Поступила в редакцию
19/IV 1988

\section{A. SOGENOVA}

\section{ORDOVIITSIUMI KARBONAATSE KIHTKONNA DETAILNE LIIGESTAMINE KAROTAAZI ANDMEIL RAKVERE FOSFORIIDIMAARDLA PIIRES}

Elektrokarotaaž (näiv eritakistuse meetodil) ja gammakarotaaž võimaldavad tunduvalt täpsustada puursüdamike põhjal määratud kihistike paksust ja lasumussügavust (joon. 2). Tabelis on näidatud karotaažikõveratel reeperkihtidele ja -kontaktidele vasta. vad iseloomulikud punktid. Dipoolse elektroprofileerimise tulemusel väljaeraldatud lōhevööndi kuuest puuraugust koosnevas ristlöikes on nimetatud punktid rahuldavalt korreleeritavad. On kirjeldatud ka kivimite sekundaarseid muutusi.

\section{A. SHOGENOVA}

\section{DETAILED SUBDIVISION OF THE ORDOVICIAN CARBONATE BEDS IN THE RAKVERE PHOSPHORITE DEPOSIT BY GEOPHYSICAL LOGGING}

Detailed subdivision of the Ordovician carbonate section is presented using gammaray $\log$ and electric $\log$ (method of the apparent resistivity) (Fig. 2). The table of the marker beds and contacts with the corresponding reference points on the wireline logs is compiled. The possibility of the correlation of the studied sections over fracture zone is shown on the profile consisting of the 6 boreholes, falling on a straight line across the low-resistivity anomaly zone obtained from measurements with dipole configuration of electrodes. Secondary alterations of the carbonate rocks within the fracture zone are
described. 